\title{
Evaluation of the Effects of Alcohol on the Heart by
}

\section{Stereological Methods}

\author{
Neşe Çölçimen \\ Department of Histology and Embryology, Van Yuzuncu Yil University, Van, Turkey
}

\begin{abstract}
Alcohol is an agent with known toxic effects on body organs and tissues. It injures heart tissue, causing arrhythmia, left ventricular hypertrophy, and sudden death. In the present study we aimed to determine ethanol's detrimental cardiac effects using the stereological technique. We enrolled 13 male Wistar albino rats. They were randomized into two groups as the Control $(n=6)$ and Ethanol $(n=7)$ groups. The ethanol group was orally administered $6.4 \%$ ethanol mixed with drinking water. The control group was subjected to no application. These procedures were continued for 18 days. At the end of the experiment the cardiac tissue was excised under anesthesia and the left ventricle was dissected. It was then subjected to the routine light microscopic histological examination procedure and embedded in paraffin. Sections of $5 \mu \mathrm{m}$ thick were taken and stained with Hematoxylin \& Eosin. In the stereological measurement the modified method of the Cavalieri principle was used. We detected the volume of left ventricular wall increase by the stereological technique, supporting the view that alcohol forms left ventricular hypertrophy.
\end{abstract}

Key Words: Ethanol, heart, rat, stereology

\section{Introduction}

Being increasingly consumed, alcohol preferentially affects skeletal and heart muscle. Heart muscle harm occurs as a consequence of heavy alcohol ingestion and is manifested as a kinds of function and metabolic abnormalities, including cardiomegaly, left ventricular hypertrophy, diastolic dysfunction, reduced ejection fractions and atrial fibrillation. (1) Arrhythmia, left ventricular dysfunction, and sudden death are among major consequences of alcoholinduced cardiovascular disorders (2). Chronic alcohol intake left ventricular dysfunction depending on the dose and duration of alcohol consumption (3). This effect is initially subclinical but later becomes manifest in the form of dilated cardiomyopathy and congestive heart failure. As a result of left ventricular systolic dysfunction, left ventricular diameter and mass index increase $(2,3)$.

Ethanol affects sarcoplasmic reticulum, sarcolemma membrane, the functions of mitochondria and contractile protein and disrupts cardiac contraction and mitochondrial oxidative phosphorylation. In addition, ethanol metabolites such as acetaldehyde and acetate may have a direct toxic effect on the myocardium (4). The pathogenic mechanisms responsible for alcoholic cardiomyopathy may be protein-aldehyde adducts, modifications of lipoprotein and apolipoprotein particles, accumulation of fatty acid ethyl esters, and oxidative stress (5).

Histologically, it causes both light microscopic (interstitial fibrosis, myocyte and nuclear hypertrophy, and myocyte necrosis) (6) and electron microscopic (fragmentation of contractile elements, edema of the sarcoplasmic reticulum, expansion of intercalated disc, and fatty deposits) (7) structural alterations of the left ventricle.

Stereology is the method of obtaining information about three dimensional structures of tissues using their two-dimensional sections. It is performed objectively and in a randomized manner so that it provides the most realistic information (8). There are many studies examining the effects of alcohol on the heart; however, unlike previous studies, we aimed to evaluate those effects with the stereological technique.

\section{Material and Methods}

Our study was conducted after its approval by your university Animal Studies Local Ethics Committee (Date: 28/06/2018 Decree No: 2018/06). It enrolled 13 two-month-old adult male Wistar Albino rats with an average weight of 190-220 gr. The rats were randomized into the Control $(\mathrm{n}=6)$ and Ethanol $(n=7)$ groups. The rats were housed in special metal lattices at room temperature under stable 


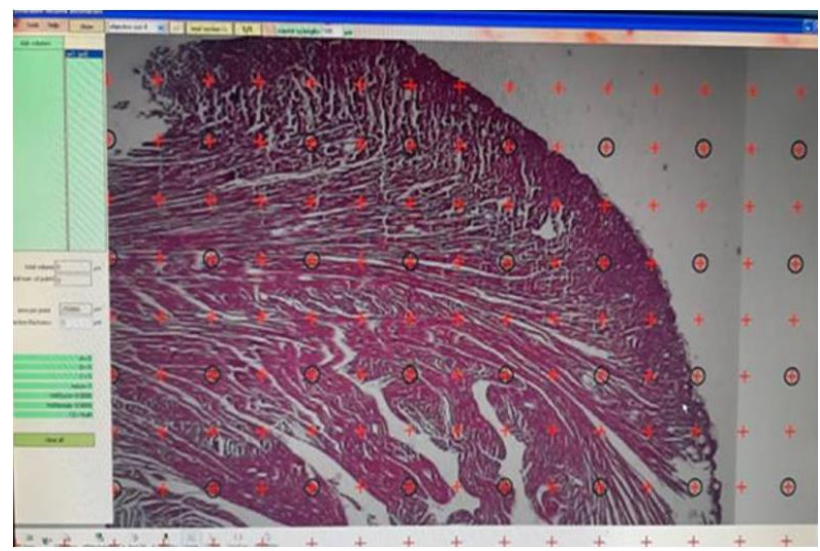

Fig. 1. Image analysis of Shtereom 1.5 program

environmental conditions $\left(21^{\circ} \mathrm{C} \pm 2{ }^{\circ} \mathrm{C}\right.$ and 12 -hour dark-12-hour light cycles). The ethanol group was orally administered $6.4 \%$ ethanol mixed with drinking water. The control group received tap water. All animals were fed with the standard fed ad libitum. The procedures were continued for 18 days. At the end of the experiment, the thoracic cavity was opened, and the heart tissue was excised under general anesthesia induced by intraperitoneal $10 \mathrm{mg} / \mathrm{kg}$ xylazine (Xylazine, Bayer, Istanbul, Turkey) and $50 \mathrm{mg} / \mathrm{kg}$ ketamine hydrochloride (Ketalar, Pfizer, Warner Lambert, Istanbul, Turkey). The left ventricle was located and dissected and fixed in 10\% buffered formaldehyde for 72 hours. Then, it was subjected to routine light microscopic histological examination methods and embedded in paraffin. A pilot study was done and the number of sections and the interslice distance were determined. Consecutive sections of $5 \mu \mathrm{m}$ thick were taken at specific intervals from each block, with the first section being randomly selected. The sections were stained with Hematoxylin\& Eosin and examined under "Nikon (Y-IM) Eclipse, Japan" light microscope.

Stereological Analysis: In the stereological measurement, the modified method of the Cavalieri principle was used $(9,10,11)$. Then, the total volume of the heart left ventricular wall was measured using a point grid provided by the Shtereom v 1.5 software package (Figure 1). The coefficient of error (CE) was calculated. The error coefficient of our stereological study was acceptable $(\mathrm{CE} \leq 0.05)(12,13)$. The density of grid points and efficiency of sampling were performed as documented in the literature (14).

Statistical Analysis: The data obtained were performed with Mann Whitney-U test. Statistical significance was set at 5\% and all statistical analyses were performed with SPSS (ver.13) statistical software.

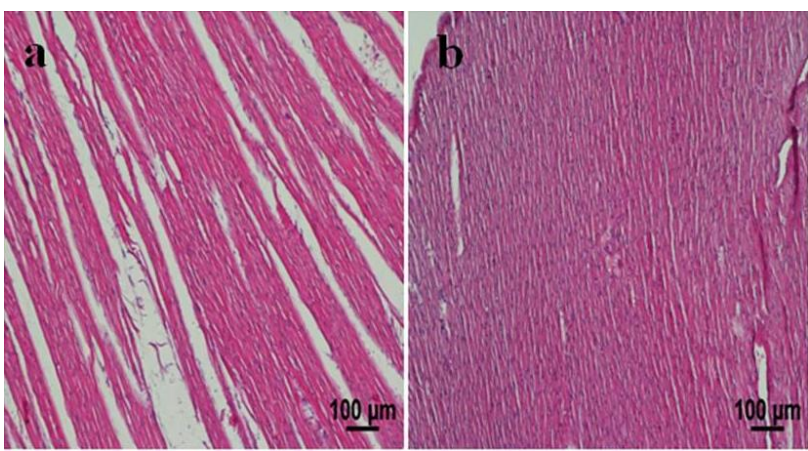

Fig. 2. a: Ethanol group heart muscle general image b: Control group heart muscle general image (Hematoylin \& Eosin, Scale bars, $100 \mu \mathrm{m}$ )

\section{Results}

Microscopic analysis revealed normal cardiac left ventricular muscle tissue in the control group. However, the heart left ventricle muscle tissue of the ethanol group had more extracellular matrix and weaker muscle fibers. In addition, the ethanol group had more space between myocytes (interstitial fibrosis), myocytolysis, and myocyte hypertrophy (Figure 2). The total volume of heart left ventricle wall was found to be increased in the ethanol group. Stereological volume measurements revealed a statistically significant increase in the ethanol group compared to the control group $(\mathrm{p}<0.05)$ (Table 1$)$.

\section{Discussion}

Alcohol exerts detrimental cardiac effects depending on the duration and amount of its use. Long-term heavy alcohol intake causes a type of non-ischemic dilated cardiomyopathy called alcoholic cardiomyopathy. Human and animal studies have indicated a direct toxic effect of alcohol on myocardium and alcohol-induced structural and functional alterations. The main histological findings of alcoholic cardiomyopathies are myocyte and nuclear hypertrophy, interstitial fibrosis, and myocyte necrosis (6). We also observed a heart muscle appearance consistent with these findings. Ethanol and its metabolites have been shown to exert toxic effects on myocyte sarcoplasm and mitochondria while they have also been ultra-structurally shown to cause edema of sarcoplasmic reticulum, fragmentation of contractile elements, dilation of intercalated discs, and formation of fat deposits (7).

The alcoholic cardiomyopathy possibly, the result of a direct toxic action of ethanol or its metabolites, or of an indirect effect due to hormonal, neurohumoral, or nutritional factors $(15,16)$. Generally, early signs of alcoholic cardiomyopathy appear to be left ventricular dilation, increased left ventricular mass, and modestly 
Table 1. Descriptive statistics and comparative results of groups

\begin{tabular}{lccccccc}
\hline & & Mean & $\begin{array}{c}\text { Standard } \\
\text { Deviation }\end{array}$ & Minimum & Maximum & Median & $\mathrm{p}$ \\
\hline Total Vol. of Left & Control &, 076 &, 43 &, 24 & 1,22875 &, 85 & 0,013 \\
Vent.Wall. $\left(\mathrm{mm}^{3}\right)$ & Ethanol & 2,18 & 1,07 & 1,29 & 4,22500 & 1,99 & \\
\hline
\end{tabular}

increased septal and posterior wall thickening. $(17,18,19)$. In agreement with the literature data, we stereologically detected an increased total volume of left ventricular wall in the ethanol-administered group compared to the control group. However, conflicting views exist regarding the effects of alcohol intake on cardiovascular health. Previous studies have shown that modest alcohol consumption produces beneficial physiological effects in healthy people. It has been demonstrated that modest alcohol intake (1-2 drink/day) reduces the incidence of cardiovascular disorders (including coronary heart disease, ischemic stroke, and amputations caused by peripheral vascular disease) (7). Furthermore, it has also been shown to be effective at improving endothelial function, reducing inflammation, plasma viscosity, and thrombocyte aggregation, and idealizing plasma lipid profile. It has been reported that 2 drinks $(20-30 \mathrm{~g})$ per day for men and 1 drink (10-15 g) per day for women provide significant cardiovascular benefits and lower heightened cardiovascular risk $(20,21)$. There is an ongoing debate about its benefit/harm ratio. Although modest alcohol consumption has been shown to produce beneficial physiological effects in healthy people, acute and chronic administration of alcohol in many human and animal models as this study, should be assumed to have hazardous effects on cardiovascular tissues.

Acknowledgments: The authors are grateful to Dr. Sıddık Keskin for statisctical evaluation of the manuscript.

\section{References}

1. Adachi J, Kudo R, Ueno Y, et al. Heart 7Hydroperoxycholesterol and Oxysterols are elevated in chronically ethanol-fed rats. J Nutr 2001; 131: 2916-2920.

2. Urbano-Marquez A, Fernandez-Sola J. Effects of Alcohol on skeletal and cardiac muscle. Muscle \& Nerve 2004; 30: 689-707.

3. Piano MR. Alcoholic Cardiomyopathy: Incidence, clinical characteristics, and patholophysiology. Review. Chest 2002; 121: 1638-1650.

4. Abacı O, Karaca OŞ, Gültekin N. Alkolik kardiyomiyopati. Derleme. Türkiye Klinikleri J Cardiol-Special Topics 2016; 9: 29-33.

5. Zhang X, Li SY, Brown RA, et al. Ethanol and acetaldehyde in alcoholic cardiomyopathy: from bad to ugly en route to oxidative stres. Alcohol 2004; 32: 175-186.

6. Spies CD, Sander M, Stangl K, et al. Effect of alcohol on the heart. Current Opinion in Critical Care 2001; 7: 337-343.

7. George A, Figueredo VM. Alcoholic Cardiomyopathy: A Rewiew. Journal of cardiac failure 2011; 17: 844-849.

8. Ünal B, Canan S, Aslan H, Şahin B, Çataloluk O, Kaplan S. Doku örneklerindeki objelerin sayılarının hesaplanmasında tarafsız stereolojik metodlar: Fiziksel disektör. Türkiye Klinikleri Tip Bilimleri Dergisi 2002; 22: 15-24.

9. Gundersen HJ, Jensen EB. The effciency of sistematic sampling in stereology and its prediction. J Microscopy 1987; 1147: 229-263.

10. Pakkenberg B, Gundersen HJG. Total number of neurons and glial cells in human brain nuclei by disector and fractionator. J Microsc 1988; 150: 120.

11. Howard CV, Reed MG. Unbiased stereology, three-dimensionel measurements in microscopy. BIOS Scientific Publishers Limited. Oxford 1998; 39-68.

12. Keller SS, Gerdes JS, Mohammadi S, et al. Volume Estimation of the Thalamus Using Freesurfer and Stereology: Consistency between Methods. Neuroinformatics 2012; 10: 341-350.

13. Gevrek F, Kara M, Rağbetli MÇ, Aslan H. Effects of prenatally exposed diclofenac sodium on rat heart tissue: a stereological and histological study. Turk J Med Sci 2015; 45: 474-480.

14. Pazvant G, Sahin B, Kahvecioglu KO, Gunes H. The volume fraction method for the evaluation of kidney: A stereological study. Ankara Üniv Vet Fak Derg 2009; 56: 233-239.

15. Badger TM, Ronis MJJ, Seitz HK, Albano E, Ingelman-Sundberg M, Lieber CS. Alcohol metabolism: role in toxicity and carcinogenesis. Alcohol Clin Exp Res 2003; 27: 336-347.

16. Schoppet M, Maisch B. Alcohol and the heart. Herz 2001; 2: 345-352.

17. Kupari M, Koskinen P, Suokas A, Ventila“ M, Suokas A, Ventila" M. Left ventricular filling impairment in asymptomatic chronic alcoholics. Am J Cardiol 1990; 66: 1473-1477.

18. Lazarevic AM, Nakatani S, Nes`kovic AN, et al. Early changes in left ventricular function inchronic asymptomatic alcoholics: relation to the duration of heavy drinking. J Am Coll Cardiol 2000; 35: 1599-1606.

East J Med Volume:25, Number:1, January-March/2020 
Neşe Çölçimen / The effect of alcohol on the heart

19. Mathews EC, Gradin JM, Henry WL, et al. Echocardiographic abnormalities in chronic alcoholics with and without overt congestive heart failure. Am J Cardiol 1981; 47: 570-578.
20. Andrade J, Gin KG. Alcohol and the heart. BC Medical Journal 2009; 51: 200-205.

21. Hines LM, Rimm EB. Moderate alcohol consumption and coronary heart disease: a rewiev. Postgrad Med J 2001; 77: 747-752.

East J Med Volume:25, Number:1, January-March/2020 